\title{
Hungary: Addressing the Life-Course Immunization Approach in the National Vaccination Policy
}

\author{
Daniela Quaggia $^{1}$, Mariano Votta ${ }^{2 *}$, Giulia Decarolis ${ }^{3}$, Máté Jankovics ${ }^{4}$, Dávid Kuti ${ }^{5}$ \\ ${ }^{I}$ Senior Project Manager at Active Citizenship Network, clo Cittadinanzattiva APS, Italy \\ ${ }^{2}$ Director Active Citizenship Network, clo Cittadinanzattiva APS, Italy \\ ${ }^{3}$ Project Assistant, European Affairs at Active Citizenship Network, Via Cereate 6, 00183 Rome, Italy \\ ${ }^{4}$ Védem, Hungary5 Preseident at Védem, Hungary
}

\begin{abstract}
*Corresponding Author: Mariano Votta, Director Active Citizenship Network, clo Cittadinanzattiva APS, Italy
\end{abstract}

\begin{abstract}
In April 2019, the Italian NGO Cittadinanzattiva, through its international branch Active Citizenship Network (ACN) launched, during the European immunization week, a new project called "European Active Citizens for Vaccination". The aim was to improve the awareness on the importance of vaccination across Europe: the scientific evidence is clear, vaccination is an essential public health tool and helps to guarantee our fundamental rights as a European citizen. ACN realized a social media communication campaign supporting and spreading awareness on the topic of life-course vaccination, videos were made in all the national languages of the involved countries (Italy, Hungary, Poland, Ireland and Spain) and then produced, shared and customized for each country. Moreover, an informative leaflet in a different language has been produced.
\end{abstract}

Civic consultations (focus groups) on the life-course immunization approach in the National Immunization Plans were held in Poland, Hungary and Spain. This article describes the main results of the focus group held in Hungary. The full report has been published in the "European Active Citizens for Vaccination: focus on Hungary (2019 - 2020)" Report, edited by Cittadinanzattiva APS (all rights reserved).

Keywords: Life-course Vaccination, Immunization, Vaccination Policy, Civic activism Hungar

Abbreviations: ACN: Active Citizenship Network

\section{INTRODUCTION}

Most vaccination programmes focus on discrete life stages such as childhood, but evidence supports a life-course approach, meaning vaccination given through all phases of life.

The life-course approach to immunization recognizes the role of immunization as a strategy to prevent disease and maximize health over one's entire life, regardless of an individual's age. It requires that immunization schedules and access to vaccination respond to an individual's stage in life.

A life-course approach has been advocated by the World Health Organization (WHO) as a model of healthcare provision that would benefit both individuals and healthcare systems. It involves looking at health as a continuum through life: a dynamic and interconnected process, as opposed to rigid life stages. It moves away from traditional approaches, where one develops and delivers vaccines in response to immediate threats for discrete age groups. Instead, investments in vaccination strategies should be based on their potential to strengthen individuals' ability to maintain good health over the course of their lives, and their impact on the prevention of other pathogens and comorbidities over time [1].

Cittadinanzattiva -Active Citizenship Network is deeply committed to contribute to raise awareness about the importance of vaccination in Italy and across Europe [2].: immunization is vital to prevent diseases and protect life. Our commitment has been appreciated by the European Center for Disease Prevention and Control (ECDC), the Agency of the European Union aimed at strengthening Europe's defense against infectious diseases that, in 2016, has decided to officially include Cittadinanzattiva in 
the ECDC Technical Advisory Group for Increasing Vaccine Coverage. As members of this Advisory Group we feel a great responsibility to commit ourselves to this issue: we believe that a widespread vaccination culture is necessary, particularly to overcome the idea that we only get vaccinated when we are young and, instead, to shift to a common knowledge linked to a life-course vaccination approach which prevents a series of diseases even during adulthood.

In April 2019, ACN launched, during the European immunization week, a new project called "European Active Citizens for Vaccination [3]". The aim was to improve the awareness on the importance of vaccination across Europe: the scientific evidence is clear; vaccination is an essential public health tool and helps to guarantee our fundamental rights as a European citizen.

\section{Materials AND Methods}

During the implementation of the abovementioned project, ACN realized two main actions:

Firstly, a social media communication campaign throughout a Video that supports and spreads this core message: "Together, as active and aware citizens, we can protect ourselves, become the champion of your future!" sending a unified, clear and strong message on the importance of vaccination directly from citizens to citizens. Videos were made in all the national languages of the involved countries (Italy, Hungary, Poland, Ireland and Spain) and then produced, shared and customized for each country. Moreover, an informative leaflet in a different language has been produced [4].

\subsection{Hungarian Video and leaflet}

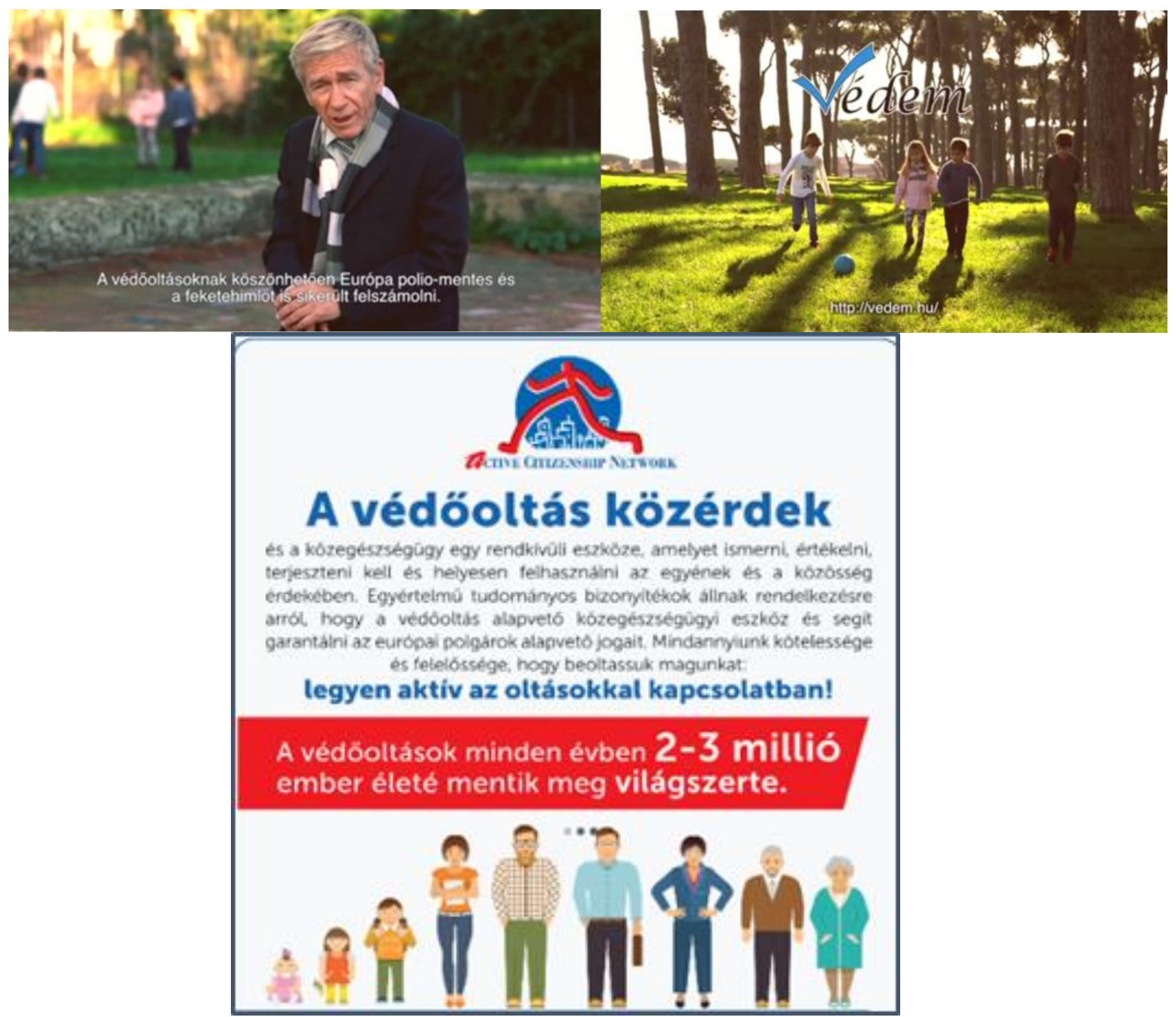

Secondly, a civic evaluation of the national immunization plans throughout the realization of three focus groups (in Spain, Hungary and
Poland) on the specific theme of the life-course immunization approach: thanks to the work and cooperation of its constituency of national 
citizens' organizations, ACN brought together around the table leaders of civic and patients association, healthcare professionals, policymakers and other stakeholders involved in each country in the administration of vaccines. The aims were to find together proposals and gather impressions, suggestions, advices and provide institutional and health care stakeholders with: the strengths/weaknesses of national policies and plans about their approach to life-course immunization approach; the common elements or specificities that affect a greater or lower success of this approach. The first countries involved were Hungary, Poland, Spain with the respective associations: Vedem Civilian for Vaccination[5], Institute of Patients' Rights and Health Education[6], Foro Español de Pacientes[7]and the Asociación Española contra la Meningitis[8].

\subsection{Glimpse of the Hungarian Focus Group}

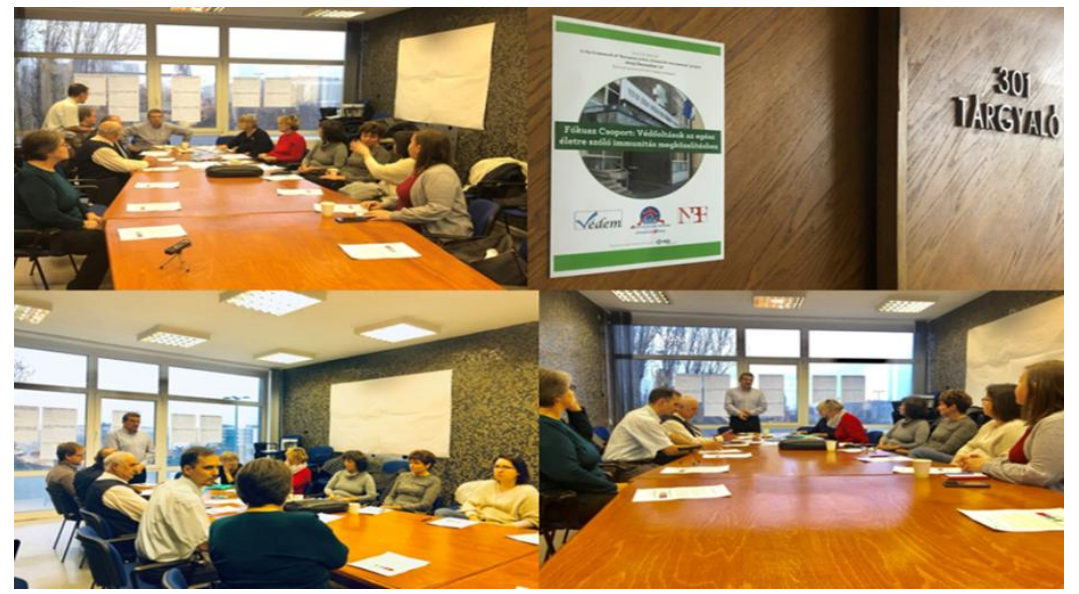

For the success of the project, ACN established and managed a scientific committee called "Steering Committee", composed of professionals, experts, and representatives of civic and patients' associations to define the

\begin{tabular}{|l|l|}
\hline George Griffin & $\begin{array}{l}\text { Federation of European Academies of Medicine } \\
\text { (FEAM) }\end{array}$ \\
\hline Professor Alberto Tozzi and Dr. Sara Ciampini & $\begin{array}{l}\text { Epidemiologist and Chief Innovation Officer, } \\
\text { Bambino Gesủ Children's Hospital, Italy. Leader } \\
\text { of the Vaccine Safety Net Web Analytics project. }\end{array}$ \\
\hline Elena Moya & $\begin{array}{l}\text { Confederation of Meningitis Organizations } \\
\text { (CoMO) }\end{array}$ \\
\hline Dafne Holt and Malcom Taylor & Coalition for Life-course Immunization \\
\hline $\begin{array}{l}\text { Silvia Romeo } \\
\text { media partner) }\end{array}$ & ThinkYoung \\
\hline $\begin{array}{l}\text { Mariano Votta, Daniela Quaggia, Alessandro Cossu, } \\
\text { Andrea Falzarano }\end{array}$ & Cittadinanzattiva - Active Citizenship Network \\
\hline
\end{tabular}

ACN worked on the creation of a questionnaire (with both closed and open questions) that was handed out to each participant in order to be used as a base of discussion during the focus group on the specific theme of life-course immunization approach in the national immunization plan; to make an exchange of information on how it is organized in that country compared with other countries: to find together proposals, suggestions, advice on that aspect.

Different people were involved, such as: leaders of civic and patient's associations, healthcare professionals, policymakers and other stakeholders implicated in the administration of messages of the social media communication campaign and the main contents of the civic evaluation. The meeting of the Steering Committee of the project was realized in Brussels at the beginning of July 2019.

Federation of European Aca

vaccines. Each focus group was led by a moderator and lasted between one and a half to three hours, depending on the number of participants. The discussions were recorded in order to be better summarized. Each participant was given two sheets with the written questions that the moderator had to ask during the discussion so that they could always see them and write down their answers in a completely anonymous way. During the debate they were given post-its of different colours to indicate their answer to the questions in a poster in the middle of the table, from which the moderator got inspiration to guide the next discussion. 
The questions were divided into two blocks, A and $\mathrm{B}$ : in part $\mathrm{A}$, the more general, all participants were asked to answer how they evaluated the awareness and support for lifecourse immunization approach in their Country, among different subjects, and how much vaccination plan in their country is designed to help maximize the individuals' ability to protect themselves from infection over the course of their lives.
In part $\mathrm{B}$, the questions regarded five key policy elements that characterize effective life- course immunization strategies (according to the IFPMA Report): Comprehensive immunization program that supports vaccine availability, Public demand for immunization, Engaged healthcare professionals, Multidisciplinary and cross-sectoral coordination and Robust data informing policies and programs.

\subsection{Image from IFPMA Report}

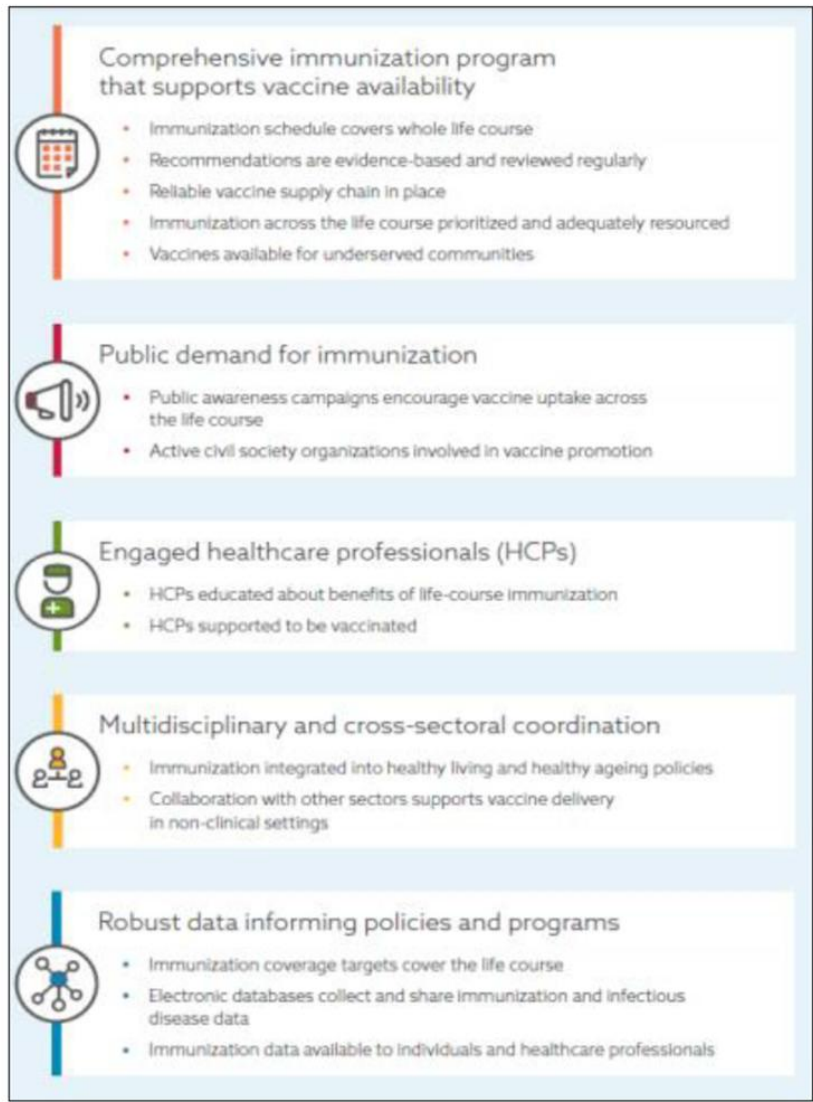

\section{RESULTS AND DISCUSSION}

The Hungarian Focus group took place in Budapest, on December 2019; the meeting was

\begin{tabular}{|l|l|}
\hline Máté Jankovics & Védem Association \\
\hline Dr. Istvánné Jankovics & Ammy Ltd \\
\hline Zita Dobiné Jankovics & Védem Association \\
\hline Hajnalka Rostásné Szabó & District Nurse \\
\hline Erzsébet Trepinszki & District Nurse \\
\hline Dr. Ágnes Hasitz & Family Doctor \\
\hline Krisztina H. Völgyes & National Stroke League \\
\hline Dr. Zsuzsa Jelenik & $\begin{array}{l}\text { Infant And Pediatrician Infectivologist -Buda Health } \\
\text { Center }\end{array}$ \\
\hline Dávid Kuti & President, „Védem” Association \\
\hline Dr. Kálmán Bartha & Vaccinologist \\
\hline Dr. István Jankovics & Virologist \\
\hline Dr. Gábor Pogány & Hungarian Patients’ Forum \\
\hline Prof. Dr. Kristóf Nékám & $\begin{array}{l}\text { President, Hungarian Allergy Association (He Was } \\
\text { Not Present At The Meeting. But He Completed The }\end{array}$ \\
\hline
\end{tabular}

organized by the Vedem Civillian for Vaccination.

The participants were: 


\begin{tabular}{l}
\hline \\
\hline Daniela Quaggia (Observer) \\
(Participants to the Civic Consultation) \\
The elements emerged from the debate showed \\
that the main aspects that should facilitate a life- \\
long approach to vaccination in Hungary are:
\end{tabular}

- There is an already good working mandatory vaccine system for children: in Hungary, vaccination against diphtheria has been mandatory since 1938. Starting from 2019 twelve types of pathogens have been used as a mandatory (and free of charge) vaccines.

- Vaccination discipline is excellent, with vaccination coverage of over $95 \%$ in all cases. The epidemiological surveillance system includes surveillance of 81 pathogens.

- The professionalism and commitment of pediatricians, GPs and nurses in the use of vaccines is excellent.

- Existence of a family-oriented social environment: the use of vaccines for families with children is considered important. Enough time and energy are spent to attend regular health counseling and children receive the right vaccinations at the right time.

- Motivated patients' associations: there are many mandatory and recommended vaccines associated with chronic infectious diseases such as diabetes, kidney disease and allergy. The organizations that protect the rights of these patients are actively involved in promoting the use of vaccines.

On the Contrary, the Main Obstacles are

- There is a wide social layer who cannot afford the necessary vaccinations: mandatory vaccinations provided to children are free of charge, however, only few vaccines for adults (flu, rabies, tetanus) are financed by the government. In addition, the general $50 \%$ support rate has dropped in recent years, so the poorer people cannot fund their vaccinations.

- Not enough clear information for citizens about the effects of the vaccines: the lack of appropriate information and a positive campaign also hinders the widespread use of the vaccine. For example, influenza vaccination for chronic patients is free of charge, but only half of the amount that can be used is administered.
Questionnaire And Wrote Suggestions.)

Active Citizenship Network

- Fear of the side effects: the Vaccine Adverse Event Reporting System (VAERS) is too complicated for citizens: the system works very well for professionals, but even though the civilian can report side effects directly to the authorities (OGYÉI), there is minimal activity from the civilian side. As a result, fake news is often spread, often supported by the media.

\subsection{About the Topic of An Immunization Schedule that Covers the Whole Life Course}

What Favors it

- Engaged professionals: regular and continuous training of health care staff, providing access to up-to-date information. At these mandatory conferences, GPs receive first-hand information, and, at the same time, consultation opportunities are available. A significant number of GPs take part in these trainings.

- Well prepared nurses: further training is also open to nurses. A significant proportion of nurses attend two or three vaccine conferences each year.

\section{What Hinders it}

- Bad communication: there is no regular communication about vaccines. In the past, the National Institute of Public Health has directed communication on vaccines, but due to reorganizations, there has been less media coverage on the topic lately.

- The number of health professionals in some disciplines has been significantly reduced, and the issue of professional replacement in the area has not been fully resolved.

- The rapid changing of the healthcare system.

Pro

- There is already a mandatory vaccine schedule for age 0-13 years old. The system of mandatory (free of charge) vaccination of children provides an opportunity to make the life-long vaccination system more efficient in Hungary. The professional background of vaccine acquisition, distribution and surveillance system is available.

- There are some professional non-official recommendations for adults. Some vaccine 
recommendations are already available in Hungary. This system should be made more compact by taking appropriate health-policy measures.

\section{Challenges}

- The evolution of infectious diseases, due to global warming and the widening of migration, puts new challenges in lifelong immunization. New challenges have emerged and are constantly emerging, for which the right professional response needs to be given as soon as possible.

- The non-official recommendation for adults reaches only few. Patient rights organizations and non-governmental organizations must be involved in communicating these new challenges properly.

\section{Suggestions}

- Discussion between the stakeholders of the national healthcare system in order to provide an effective response, information channels must be found to help healthcare organizations in different areas to develop an action plan for lifelong vaccination based on professional consensus.

- Make an official recommendation that can be widely distributed. The professional organizations should be made aware of the importance of lifelong vaccination, and they should help to formulate a new proposal by providing them with accurate information.

- To get national/international funding: In order to achieve these goals, it is important to look at the possibilities of national and international founds in this field and to seek contacts with organizations in other European Union countries. It should be signaled to decision makers that the previous 50\% support for adult access to vaccination should be restored.

\subsection{About Recommendations in National Immunization Programmes for Patients with Specific Chronic Conditions}

What Favors it

- Patient associations: patient organizations have accurate information about the data of patients with chronic diseases. These data provide professional with information, and moreover, patient organizations are aware of the financial needs they have for patient care. These data can be used as a starting point for developing professional recommendations.

- Free influenza vaccine for patients with chronic illnesses. The excellent organization and management of influenza surveillance and vaccination, which has been working well for decades, could provide an appropriate base for the delivery of other vaccines to target groups and for the organization of a control monitoring system.

\section{Obstacles}

- Financials or additional funding should be allocated to the insurance system for each disease group.

- No specific recommendation for patients with chronic illnesses. It would be necessary to develop a formal recommendation for people with various chronic conditions, which is also available to doctors and patients.

\section{Suggestions}

- To improve specific recommendations, in cooperation with healthcare professionals and civic/patients' associations. For the recommendation to be made, political decision-makers must be given the appropriate financial background

- Feasibility studies should be conducted based on the available data for the individual patients. Professional decisionmakers should make recommendations in the light of these studies.

- To get national/international funding for immunization programs of patients with specific chronic conditions.

\subsection{About Public Awareness Campaigns}

\section{What Favors it}

- Citizens are open to more information on this topic. Vaccination rates in Hungary are high, especially about childhood vaccines. Most citizens are aware that the use of vaccines is important for maintaining health.

- There were successful campaigns in the former years. It should be mentioned that vaccination against pneumococci for elderly people has been successful over the past decades. There has been a similar successful campaign on HPV vaccination.

\section{What Hinders}

- There are no public awareness campaigns about adult's vaccination. Experience from 
previous successful campaigns should develop a comprehensive, continuous information system for all ages and all communication channels.

\section{Suggestions}

- National/international funding for campaigns of civic associations. Need to create the right financial background for campaigns.

\subsection{About Active Civil Society Organizations Promoting Immunization Across the Life Course}

\section{What Favors it}

- Patients (with chronic illnesses) associations are interested in life course immunization. Patient organizations have an interest in developing a lifelong vaccination plan and implementing approved programs.

- There are scientific materials available, though often not even known by doctors. They can be a good basis for promotion. The first step is to reach all healthcare workers.

\section{What Hinders}

- No strong civic promoting activity. Individuals should also be interested in lifelong vaccination projects. Information should be provided to chronic patients in all areas.

- Scientific materials are difficult to understand. Information for professionals should be translated into lay language for citizens. The description of the importance of lifelong immunization needs to be simple.

\section{Suggestions}

- Strong cooperation between professionals and civic associations. It is necessary for healthcare workers to consider civic associations as partners. Through regular consultation, build together a successful communication.

- Patients' associations should cooperate with VÉDEM to translate scientific materials (handouts, infographics) for civilians. Patient organizations should not be involved individually, but jointly in the development and dissemination of professional information at the appropriate level. The "VÉDEM" helps coordinating this work.

\subsection{About Health Care Professionals Education about Benefits of Immunization Across the Life Course}

\section{What Favors it}

- Regularly organized trainings about vaccination. In Hungary, three national continuing education courses on vaccines are organized annually. Many GPs and nurses are involved.

- There are many good and valid materials. Continuously published specialist books and numerous professional publications supporting family doctors in vaccination education.

\section{What Hinders}

- There are no additional regional courses beyond national trainings. Even though there are enough specialists in all fields to conduct the courses.

\section{Challenges}

- No mandatory education about life course immunization for healthcare professionals. Lifelong immunization programs should be highlighted in the training materials.

- Different social problems in different regions: a different communication strategy is needed due to the higher rate of unemployment.

\section{Suggestions}

- Online education: Hungary has a high proportion of the population who regularly use the internet. Especially the younger ones. However, nowadays more and more seniors have access to online information because the government is organizing free courses for them.

- To help vaccine- supporting associations to implement online courses. The material of the online courses should be developed and made available in all regions. It would be important to build a nationwide network where local professionals and local civilians can also validate their online courses through face-to-face meetings. Online courses must be certified by those who have successfully completed the course.

\subsection{About the Support to Health Care Professionals to be Vaccinated}

\section{What Favors it}

- Expectation form patient's side: many patients expect their GPs to be vaccinated 
with a vaccine to prevent the disease. Especially during the flu season and measles appearances, this tendency intensified.

- due to the low number of healthcare workers, it is essential to maximize the human resources (prevent illnesses). For healthcare workers, the employer reviews the medical fitness every year. Vaccinations are also checked during these reviews.

\section{What Hinders}

- Bad practice: unfortunately, due to bad practice, GPs do not take their own immunization protocol seriously. There is often a misconception that the "natural immunity" of health workers is better than the immunity of patients.

- It is hard to communicate with healthcare professionals on health topics. Appropriate regulations and the citizens well-being should help ensure that health workers also use lifelong immunization as they treat sick people who are more susceptible to infection.

\section{Suggestions}

- To change bad habits: it is a long and laborintensive process. Based on the habits and needs of healthcare workers, a model program for successful change should be developed. It helps, if the program minimizes the time and effort spent by healthcare professionals.

- Free life-course immunization for healthcare workers. First, vaccinations should be made available to healthcare workers free of charge, as well as give them opportunities for administration on their workplace. The "VÉDEM" can provide community space for vaccinated healthcare professionals to promote their activity.

\subsection{About Immunization Integrated into Healthy Ageing Policies}

\section{What Favors it}

- Increasing number of elderly people who actively care about their own health. In Hungary, the health attitude of the elderly has recently changed. They have more and more opportunities to be active participants to maintain their health.

- There are some free vaccines for elderly people (flu, pneumococcus). It is a good practice, that there are vaccines which are easily available for the elderly. Building on this, even more vaccines should be made easily available to the elderly and not so elderly too.

\section{What Hinders}

- Over the age 60, the therapy suppresses the prevention: unfortunately, a higher percentage of older people already suffering from a chronic disease, so their health care activities are focused on treating the disease.

- It's hard to motivate aged people

- It is not enough to deal with the idea of healthy ageing, in old age. The awareness campaigns should be extended to the "younger" adults.

\section{Suggestions}

- Better communication about the importance of a relation between healthy ageing and immunization. There is a need for a professionally supported communication campaigns that makes it clear: immunization plays a significant role in healthy ageing.

- Improve communication channels through younger relatives. The family responsibility for each other is an effective medium for learn new information about immunization. Members of the younger generation can help keep the older ones up to date. The "VÉDEM" can help young people by giving them clear information for seniors.

\subsection{About Vaccine Delivery in Non-Clinical Settings}

What Favors it

- The good practice of vaccination campaigns in schools (HPV, Hepa B). In Hungary, the school health care system is regulated by law. In this context, some mandatory vaccinations are administered in schools for the 6-13 age groups. The school doctor and the school nurse are responsible for the organization and administration, supported by the school management. It would be obvious to improve the existing system. School vaccination can be a good model for vaccination in other non-health facilities. One of these locations could be pharmacies.

\section{What Hinders}

- The legal background is not completely regulated: outside school (for mandatory vaccination), vaccines can only be given in health care facilities. This is regulated by law. 
- Patients only trust doctors: vaccination outside health care facilities requires not only equipment and facilities, but also properly trained staff. However, because of doctors' overload, this requires qualified health care professionals. One of the main barriers to this is the psychological fact that in Hungary people only trust in doctors and vaccination requires a relationship of trust.

\section{Suggestions}

- The range of the persons authorized to vaccinate should be extended. Under current law, vaccines should only be administered by a physician. In exceptional cases, however, the physician may authorize a qualified health care professional to administer the vaccine, but this is the professional responsibility of the physician. In order to allow a qualified health care professional to administer the vaccine, this regulation needs to be changed. At the same time, responsibility levels need to be redefined, specifically regarding the circumstances of responsible administration and possible side effects. A new liability insurance system needs to be developed.

- Accredited trainings about vaccine administration for other healthcare workers. After changing the legal bases, the professional system must be built up. The minimum professional conditions for vaccination outside health care facilities should be defined. A safe hospital background should be provided when adverse reactions occur. Appropriate training and further training systems should be developed for qualified nurses.

\subsection{About Coverage Targets in All Groups Across the Life Course}

\section{What Favors It}

- Well-developed vaccination schedule under age 13 which guarantee the high level (over 95\%) coverage. This should also be developed in connection with adult vaccination.

- Whole range of vaccines are available for life course immunization. In Hungary, all vaccines that are available for life-long vaccination are registered, has a marketing authorization and available in pharmacies (all vaccines are subject to prescription).

\section{What Hinders}

- There are not yet developed vaccination plan over age 13 years old. Professional and non-governmental organizations should propose the introduction of lifelong vaccination. The proposal must be accepted by political decision-makers and provide a legislative background. A lifelong vaccination program should be integrated into the system of national public health preventive projects.

\section{Challenges}

- Citizens don't know more vaccinations beyond the mandatory ones: mandatory vaccines are given to people, so they do not feel the need to be informed about vaccinations. Most people do not even hear about the need for adult vaccinations.

- High price of vaccines If they can still get credible information about not mandatory vaccines, the high price will easily scare away them.

\section{Suggestions}

- Awareness and vaccination campaigns for citizens over 25 years. Most importantly, adults should seek the appropriate vaccine for them based on relevant professional information. This requires continuous information. We need campaigns in every area of the media. Campaigns should involve civic associations alongside professionals.

- The government should reduce the cost of vaccines. Previously, all prescription vaccines received 50\% support from the state health insurance. There is no financial support currently. This makes it difficult for citizens to have access to vaccines.

\subsection{About Timely and Accurate Data on Vaccine Uptake}

\section{What Favors it}

- Well-developed vaccine uptake monitoring system under age 13. The documentation system for mandatory vaccinations is excellent in Hungary. The patient has a paper-based health-record document. The physician will enter the vaccine name and lot number and the date of administration each time the vaccine is administered. This information is also stored in the patient's electronic database. These data are always available when adverse reactions are reported.

- The current paper-based system is perfectly run by the nurses, as evidenced by the high vaccination coverage rate. There is great 
potential for further development and expansion.

\section{What Hinders}

- There are not yet developed vaccine uptake monitoring system over age 13 years, except flu, tetanus and rabies. Non-mandatory vaccines will only be registered if requested by the patient in connection with his or her travel. This data is also electronically recorded by the International Vaccine Centre. Otherwise, when the vaccine is given free of charge (for examples Flu for patients suffering chronic diseases or in case of rabies and tetanus risks, the appropriate vaccine) the physician administering the vaccine uptakes will only confirm the vaccine on the outpatient document.

- No human resources for developing the double documentation system electronic and paper based. It causes an unnecessary burden on healthcare workers.

\section{Suggestions}

- Health decision-makers should adopt a unified, transparent, traceable electronic documentation system for vaccination monitoring.

- Documentation must be recorded and stored in an electronic database. Everyone in Hungary has an electronic client gateway system where some health data is already stored. An appendix of this document could be the personal vaccination record.

- Developing an IT based infrastructure.

\subsection{Final impressions and reflections:}

- There is a well-operating vaccination system for children, but there are some hinders and problems.

- There is not enough clear information for citizens about immunization, there should be an information system organized by civic associations with strong support of healthcare professionals and politicians.

- The vaccine uptake monitoring data should be fully digitalized.

- The lifetime immunization approach should be integrated to the national education plan for elementary school students.

- The main problem in Hungary is financial based, it would be great to increase the funding of immunization.

\section{CONClusion}

The experience and the main outputs of the project suggest how relevant it is, in the field of vaccination, to develop a policy on lifelong vaccinations rather than only focus on child vaccination only because it is mandatory. The initiative testifies the positive role played by health professionals as well as private and public actors involved in the policy making. Despite their tendency to criticize the failures and weaknesses existing within the system, they have demonstrated their contribution giving plenty of advice and suggestions on how to improve the actual vaccination system in Hungary.

Moreover, the project shows that the role of these focus groups is that of identifying not only emerging problems, but also possible solutions to denounce what does not work properly and to appreciate what proves to be successful. As for us, we have been committed to this topic and we will work hard to reinforce vaccination policies all around Europe.

\section{ACKNOWLEDGEMENTS}

This initiative, in Hungary, was possible thanks to Vedem Civilian for Vaccination.

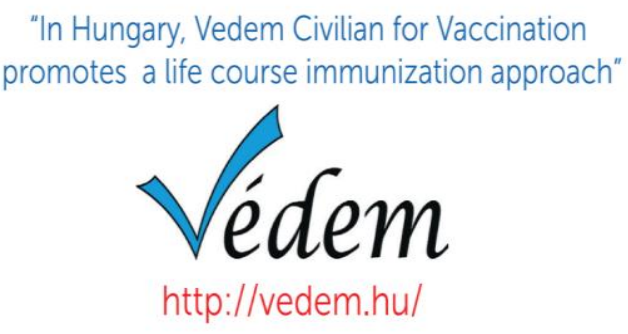

\section{REFERENCES}

[1] IFPMA, Implementing a Life -Course Approach to Immunization", 2019. https:// www.ifpma. org/wpcontent/uploads/ 2019/08/ IFPMA_HPP_Life_Course_Immunization_Full _Report.pdf

[2] Active Citizenship, The engagement of Cittadinanzattiva on vaccination, official website http://www. activecitizenship. net/ patients-rights/projects/278-the-engagement-ofcittadinanzattiva-on-vaccination.html

[3] Active Citizenship, European active citizens for vaccination, 2019. official website http://www. activecitizenship.net/patients-rights/ projects/ 294-european-active-citizens-for-vaccination2019.html

[4] All the materials are available on www.activecitizenship.net/patients-rights/ projects/294-european-active-citizens-forvaccination-2019.html 
[5] Hungarian association Vèdem, official website https://vedem.hu/ Polish association, official website http:// ippez.pl/

[6] Spanish association, official website https:// forodepacientes.org.

[7] Spanish association, official website https:// www.contralameningitis.org/la-asociacion

Citation: Daniela Quaggia, Mariano Votta, Giulia Decarolis, Máté Jankovics, Dávid Kuti, Hungary: Addressing the Life-Course Immunization Approach in the National Vaccination Policy. ARC Journal of Nursing and Healthcare. 2020; 6(2):12-22. DOI: doi.org/ 10.20431/2455-4324.0602003.

Copyright: (c) 2020 Authors. This is an open-access article distributed under the terms of the Creative Commons Attribution License, which permits unrestricted use, distribution, and reproduction in any medium, provided the original author and source are credited. 